\title{
Palatability: response to nutritional need or need-free stimulation of appetite?
}

\author{
Martin R. Yeomans ${ }^{1 *}$, John E. Blundell ${ }^{2}$ and Micah Leshem ${ }^{3}$ \\ ${ }^{1}$ Department of Psychology, School of Life Sciences, University of Sussex, Brighton, Sussex BN1 9QG, UK \\ ${ }^{2}$ PsychoBiology Group, University of Leeds, Leeds, UK \\ ${ }^{3}$ Psychology Department and Brain and Behavior Centre, University of Haifa, Israel
}

\begin{abstract}
The traditional view of palatability was that it reflected some underlying nutritional deficit and was part of a homeostatically driven motivational system. However, this idea does not fit with the common observation that palatability can lead to short-term overconsumption. Here, we attempt to re-evaluate the basis of palatability, first by reviewing the role of salt-need both in the expression of liking for salty tastes, and paradoxically, in dissociating need from palatability, and second by examining the role of palatability in short-term control of appetite. Despite the clarity of this system in animals, however, most salt $(\mathrm{NaCl})$ intake in man occurs in a need-free state. Similar conclusions can be drawn in relation to the palatability of food in general. Importantly, the neural systems underlying the hedonic system relating to palatability and homeostatic controls of eating are separate, involving distinct brain structures and neurochemicals. If palatability was a component of homeostatic control, reducing need-state should reduce palatability. However, this is not so, and if anything palatability exerts a stronger stimulatory effect on eating when sated, and over-consumption induced by palatability may contribute to obesity. Differential responsivity to palatability may be a component of the obese phenotype, perhaps through sensitisation of the neural structures related to hedonic aspects of eating. Together, these disparate data clearly indicate that palatability is not a simple reflection of need state, but acts to promote intake through a distinct hedonic system, which has inputs from a variety of other systems, including those regulating need. This conclusion leads to the possibility of novel therapies for obesity based on modulation of hedonic rather than homeostatic controls. Potential developments are discussed.
\end{abstract}

Palatability: Salt: Appetite

What makes a food palatable? Does palatability reflect internal nutritional state? Or does hedonism promote intake independent of nutritional needs? These and related questions about the relationship between palatability and controls of nutrient intake are central to our understanding of how sensory factors are involved in appetite regulation. However, despite many reviews (Young, 1967; Kissileff, 1976; Le Magnen, 1987; Naim \& Kare, 1991; Drewnowski, 1998; Yeomans, 1998), theories (Davis \& Levine, 1977; Cabanac, 1989; Berridge, 1996; Berridge \& Robinson, 1998) and debates (Kissileff, 1990; Ramirez, 1990; Rogers, 1990), there is still a lack of consensus on the nature of palatability. The recognition that a positive energy balance is a contributory factor in the current increased incidence of obesity (Doucet \& Tremblay, 1997; Jequier \& Tappy, 1999), and that over-consumption of palatable foods may contribute to this positive energy balance (Blundell \& Cooling, 2000), make resolution of the nature of palatability an urgent issue.

Theories about the nature of palatability fall into two broad groups. One group of theories suggests that palatability reflects an underlying biological need for the nutrient predicted by the sensory properties of the ingestant. Accordingly, liking for sweet tastes when hungry can be interpreted as an expression of energetic needs (Cabanac, 1971, 1989), while salt deprivation may enhance palatability of salty tastes (Denton, 1982; Berridge et al. 1984). The second group of theories relates palatability to reward processes that may operate, at least to some extent, independently of need state. Both groups of theories have contributed to the notion of allostasis, wherein needstates can be anticipated in the absence of current need. The first two sections of the current review evaluate the recent literature relating to these different theoretical positions, initially by reviewing evidence for palatability of salty tastes as a reflection of need-state, and then extending this discussion to foods where the relationship between sensory properties and nutrient consequences are mainly acquired. The general conclusion is that in neither case can palatability be explained adequately by need-state models alone, and a more integrative model combining hedonic and need-state-driven components is required. This then leads into a discussion of the implications of need-free stimulation of appetite by palatability for obesity, and potential treatments of obesity.

One problem in evaluating effects of palatability is defining the specific sensory component that is being evaluated. For primary tastes, which have a direct relationship 
with a specific nutrient (thus salty tastes always predict $\mathrm{Na}$ ), this definition is clear. For more complex flavours, there is little evidence that palatability reflects innate flavour preferences, with the exception of sweet tastes (Steiner et al. 2001; Beauchamp et al. 2002; Drewnowski, 2002), and thus palatability must reflect the outcome of past experience. A full discussion of the mechanisms underlying the development of palatability is beyond the scope of the present review, and have been reviewed elsewhere (Rozin \& Vollmecke, 1986; Zellner, 1991; Sclafani, 1999; Mela, 2000). Instead, we concentrate on the mechanisms relating to the expression of palatability, and its effects on immediate appetite.

\section{The biological determinants of salt palatability}

The beauty of the phenomenon of increased palatability of salt consequent on bodily $\mathrm{Na}$ deficit stems from its patent adaptive significance, the unequivocal definition, to the ion, of the object of the palatability changes, and the mystery of how a naive animal can find the remedy to its specific affliction: by taste. Yet studies on human subjects on the determinants of individual variability in salt palatability and intake have concentrated on acculturation and learning, especially in infancy and childhood. These have shown how a particular salty food becomes preferred, but they have not revealed the determinants of individual variability in the palatability of salt (Harris et al. 1990; Beauchamp et al. 1991; Kanarek et al. 1995; Leshem \& Rudoy, 1997).

This directs us to consider biological determinants of salt palatability. In many animals, including primates (Denton, 1982; Denton et al. 1993, 1995), the palatability of salt varies inversely with its availability to the body, and it is believed to be the primary mechanism driving increased $\mathrm{Na}$ intake (Denton, 1982; Berridge et al. 1984; Berridge \& Schulkin, 1989; Epstein, 1991; Schulkin, 1991; Johnson \& Thunhorst, 1997). But natriuphillic animals also have a spontaneous avidity in the absence of immediate physiological need (Denton, 1982; Epstein, 1991) that can bear the traces of perinatal (Denton, 1982; Nicolaidis et al. 1990; Crystal \& Bernstein, 1995; Leshem et al. 1996; Vijande et al. 1996; Arguelles et al. 1999; Leshem, 1999) or adult Na-loss as a long-term enhancement of salt palatability (Falk, 1966; Sakai et al. 1987, 1989; Rowland \& Fregly, 1988). A coherent physiological model of the determinants of salt intake has emerged, including the notion that acute activation of the brain renin-angiotensin system conjointly with peripheral aldosterone, as by $\mathrm{Na}$ deficit, can induce both the acute and enduring increases in Na palatability (Fluharty \& Epstein, 1983; Sakai et al. 1987, 1989; Epstein, 1991; Schulkin, 1991; Johnson \& Thunhorst, 1997), possibly involving changes in dendritic morphology and neurochemistry (Roitman et al. 2002).

\section{Sodium deficit and palatability}

Perhaps the most evocative demonstration of this change in palatability is the rat's response to the taste of salt when in Na-deficit: its oral, lingual and forelimb movements become similar to those expressed in response to sugared water
(Berridge et al. 1984; Berridge \& Schulkin, 1989; Curtis et al. 2001) and its neurons respond analogously (Jacobs et al. 1988). Since the same circumstances bring about increased intake of $\mathrm{Na}$, herein, our working assumption is that increased intake is driven by increased palatability. The taxonomy of $\mathrm{Na}$ palatability and intake is outlined in Fig. 1. It requires some clarification: both $\mathrm{Na}$ hunger and spontaneous $\mathrm{Na}$ appetite are considered to be innate responses. The enhanced spontaneous appetite enduringly replaces the spontaneous appetite as a consequence of experienced $\mathrm{Na}$ deficit, and is viewed as an expression of biological preparedness triggered by the earlier deficit (Epstein, 1991; Schulkin, 1991). Actually, expression of $\mathrm{Na}$ hunger, or even frank Na deficit, are not necessary for induction of enhancement: surging of the hormones from a state of $\mathrm{Na}$ loss is a sufficient condition (Sakai et al. 1989). This is important, as we shall see later, because it releases us from positing a frank $\mathrm{Na}$ deficit as the antecedent of long-term enhanced palatability.

The functional significance of these palatability changes differs: the acute increase in Na palatability enables resolution of the immediate natriuretic challenge. Epstein (1991) has suggested that the need-free spontaneous avidity for salt is also regulatory, motivating the Na-dependent animal to seek and learn about sources of $\mathrm{Na}$ in its surroundings, and to maintain adequate intake. He also suggested that the enhanced appetite is an expression of biological preparedness, hormonally organised, working as a hedge against salt deficit in an environment of proven scarcity, by further prioritising the seeking and memorising of $\mathrm{Na}$ resources (Epstein, 1991). Environmental scarcity might be extended to include an individual vulnerability to Na privation, for example, a tendency to dehydration, perspiration, diarrhoea or vomiting, whether of constitutional or behavioural origins. Schulkin (2003) has recently argued elegantly for the enhanced spontaneous $\mathrm{Na}$ appetite as a prime example of allostasis: homeostasis broadened to encompass preparedness and anticipatory responses. This broader view clarifies how Na need, long past, nevertheless determines contemporary $\mathrm{Na}$ palatability.

\section{Do physiological mechanisms regulate sodium palatability in human subjects?}

Similarities to salt appetite in animals are suggestive: in both human subjects and animals, $\mathrm{Na}$ is a basic taste

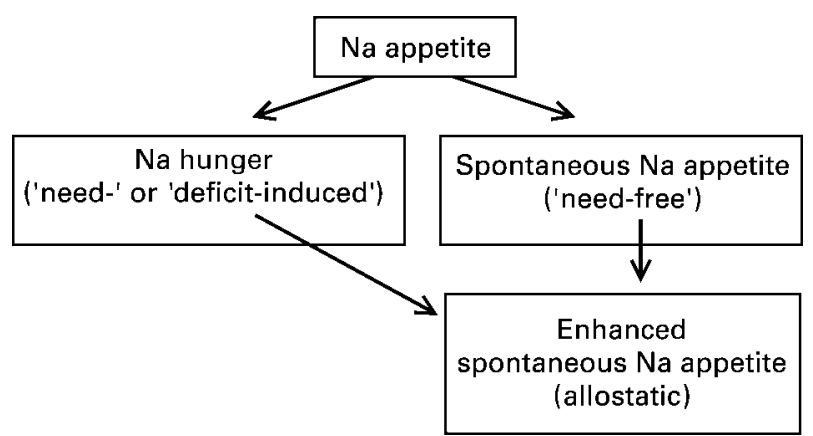

Fig. 1. Taxonomy of $\mathrm{Na}$ appetite. Spontaneous $\mathrm{Na}$ appetite becomes enhanced enduringly if $\mathrm{Na}$ hunger is experienced. (See p. S4.) 
modality, and the hormones of $\mathrm{Na}$ conservation, aldosterone and angiotensin II, regulate $\mathrm{Na}$ balance (Nose et al. 1988; Verbalis, 1990). Like animals, man appears to have the spontaneous avidity for salt, and as in rats, perinatal mineralo-fluid loss causes a long-term enhancement of Na palatability (Crystal \& Bernstein, 1995, 1998; Stein et al. 1996; Leshem, 1998; Leshem et al. 1998; Crystal et al. 1999; Kochli et al. 2002).

\section{Sodium need in human subjects}

Human instances of $\mathrm{Na}$ privation are consequent upon adrenal or hormonal pathology, haemorrhage, dehydration, diarrhoea, vomiting, neonatal hyponatraemia and exertioninduced $\mathrm{Na}$ losses. However, unlike animals, Na-deficient human subjects have generally failed to show a robust increase in salt intake after severe $\mathrm{Na}$ restriction (Mattes, 1997). The most cited reports of such a response in human subjects are practically anecdotal: a posthumous case report (Wilkins \& Richeter, 1940), a statement in a study of Addison's disease (Henkin et al. 1963) and a report that one of four $\mathrm{Na}$-deficient volunteers craved salt (McCance, 1936).

More recent and empirical reports are accumulating modest evidence for physiologically bound $\mathrm{Na}$ palatability in human subjects. Although some studies found that haemodialysis, during which $\mathrm{Na}$ levels are reduced from high-normal to low-normal, did not increase Na palatability (Shepherd et al. 1986; Farleigh et al. 1987), others found suggestive effects of haemodialysis (Leshem \& Rudoy, 1997) and of neonatal or adult natriuretic treatment (Beauchamp et al. 1990; Mattes et al. 1990; Leshem et al. 1998). Exercise does seem to increase Na palatability (Takamata et al. 1994; Leshem et al. 1999) and conditioning of a $\mathrm{Na}$ preference after exercise may be related to the amount of perspiration, suggesting a relationship between $\mathrm{Na}$ lost and increased palatability conditioned via the restorative role of $\mathrm{Na}$ on hydration and electrolyte balance (Wald \& Leshem, 2003). Most recently, we have found increased $\mathrm{Na}$ palatability in those congenital adrenal hyperplasia patients who are salt-wasting and not stabilised by medication (Kochli et al. 2002). Together with a report that insensible $\mathrm{Na}$ preload reduces salt intake (Jacobs et al. 1988), these studies constitute fair, but not overwhelming, evidence that salt palatability is modulated by bodily $\mathrm{Na}$ availability.

\section{Enhancement of spontaneous salt palatability}

Surprisingly, the most replicated effect is not of $\mathrm{Na}$ hunger, but that of the enduring enhancement of $\mathrm{Na}$ palatability following on putative perinatal $\mathrm{Na}$ privation in utero by maternal vomiting during pregnancy (Crystal \& Bernstein, 1995, 1998; Leshem, 1998; Crystal et al. 1999; Kochli et al. 2002) or due to infantile vomiting and diarrhoea (Leshem, 1998) or to electrolyte-deficient infant formula (Stein et al. 1996) (recall that frank $\mathrm{Na}$ loss is not necessary for enhancement, a surge of the hormones is a sufficient condition (Sakai et al. 1989)). Negative results from a series of studies examining Na palatability in human subjects who suffered some form of putative $\mathrm{Na}$ privation in adulthood, as by hyperhidrosis, multiple blood donations, multiple births or dehydration during military training, showed no increases in Na palatability (M Leshem, unpublished results). Together, therefore, these findings suggest that variability in spontaneous $\mathrm{Na}$ palatability may be largely determined by early physiological events.

\section{Sodium appetite and the palatability of salt in human subjects}

These are interesting advances in charting the similarities between animals and human subjects, and they impart biological credence to the phenomenon. Yet they rest on the assumption that man has a $\mathrm{Na}$ appetite. But do we? The rationale for a human salt appetite rests on the widespread use of salt in food, but mere reflection reveals the inadequacy of this argument that could equally be applied to sugar, pepper or ketchup. Alternative interpretations might emphasise the utility of salt as a 'taste enhancer' or taste modulator (Epstein, 1991; Breslin \& Beauchamp, 1995). Moreover, the fact that unlike animals, human subjects do not find pure salt or its aqueous solution palatable (Pangborn \& Pecore, 1982; Huggins et al. 1992) is troublesome for the proposition of a human salt appetite.

To advocate a human salt appetite, it would be necessary to demonstrate a commonality of palatability changes among the multiple forms of ingested $\mathrm{Na}$. Indeed, determining the palatability of salt in human subjects is complicated by the absence of a ubiquitous definition of salt appetite. Palatability of $\mathrm{NaCl}$ in aqueous solution (used in animal research) may not be a good predictor of palatability of salt in food (Pangborn \& Pecore, 1982; Huggins et al. 1992).

Moreover, if there is commonality of salt intake, it should extend to both conscious and unconscious $\mathrm{Na}$ intake that characterises human subjects (Shepherd et al. 1989). Unconscious intake includes $\mathrm{Na}$ inherent in foods or added in industrial processing or cooking, and insofar as the food choices an individual makes may be conditioned by post-ingestive consequences of, inter alia, their $\mathrm{Na}$ content, unconscious $\mathrm{Na}$ preference may be partly conditioned (Wald \& Leshem, 2003). Conscious salt intake comes from a number of sources, e.g. salting at table, choice of salty food items in meals and consumption of salty snacks.

Because of these considerations, to examine ' $\mathrm{Na}$ appetite' in human subjects, we employ a number of tests of salt palatability and combine them to provide a measure of the overall 'appetite' for salt. A test of salting of soup provides a measure of conscious salt use. The technique we employ, of mixing solutions, ensures that the result is driven by palatability rather than habit (Pangborn \& Pecore, 1982; Greenfield et al. 1983; Beauchamp et al. 1987; Shepherd et al. 1989). Conscious salt use is also evaluated by asking participants how much salt they add to each of fifty food categories or items (Leshem, 1998). To evaluate their conception of the palatability of salt relative to others, we ask how much they like salt; to obtain a measure of palatability for high salt concentrations, we monitor intake of salty snacks (Crystal \& Bernstein, 1995); to obtain an indication of unconscious salt intake, 
we use dietary recall. We derive the fractional excretion of $\mathrm{Na}$, an index sampling recent $\mathrm{Na}$ intake. Finally, to measure the hedonic response to $\mathrm{NaCl}$ we spray six concentrations into the mouth and score the responses on a linear scales. As a control, we obtain scores of sweet palatability in analogous tests.

The intercorrelations of these different indices can indicate the validity of a general salt palatability. Factor analysis of data obtained from eighty-two young people (half of them diagnosed with congenital adrenal hyperplasia) provided two main factors accounting for the palatability of salt, and, importantly, they were distinct from that accounting for the palatability of sweet (Table 1; Kochli et al. 2002; for another example, see Leshem 1998). Since the factors include questionnaires, behavioural tests and physiological measures of palatability, representing conscious and unconscious modes of salt intake in different ingestive contexts (snacks, meals), this commonality suggests that to some extent salt palatability is assessed independently of its food vehicle. This is further support for regulated $\mathrm{Na}$ palatability.

Thus, of the two appetitive mechanisms for combating $\mathrm{Na}$ deficit, $\mathrm{Na}$ hunger may be rarely observed in human subjects (if only because of our salt-redundant environment), but the spontaneous, need-free appetite, which may prevent deficit arising, is more evident. Human subjects seem to regulate this latter appetite for salt by taste and habit (Bertino et al. 1982, 1986; Pangborn \& Pecore, 1982; Greenfield et al. 1983; Cowart \& Beauchamp, 1986; Beauchamp et al. 1987, 1991; Harris et al. 1990; Ayya \& Beauchamp, 1992; Huggins et al. 1992; Kanarek et al. 1995). However, evidence is accumulating that it may also be regulated by alterations within the normal range of body salt levels (Huggins et al. 1992; Takamata et al. 1994; Leshem \& Rudoy, 1997; Leshem et al. 1999; Kochli et al. 2002; Wald \& Leshem, 2003), and that it can be enhanced enduringly by early Na challenge (Crystal \& Bernstein, 1995, 1998; Stein et al. 1996; Leshem, 1998; Leshem et al. 1998; Crystal et al. 1999; Kochli et al.

Table 1. Rotated factor matrix of tests of salt and sweet palatability

\begin{tabular}{|c|c|c|c|c|}
\hline Factor... & 1 & 2 & 3 & 4 \\
\hline Variance explained (\%)... & 21 & 16 & 13 & 11 \\
\hline Hedonics of oral $\mathrm{NaCl}$ spray† & 0.724 & & & \\
\hline $\begin{array}{l}\text { Amount of salt added to } \\
\text { soupt }\end{array}$ & 0.721 & & & \\
\hline Licking pure salt* & 0.710 & & & \\
\hline Sweeten food* & & $0 \cdot 845$ & & \\
\hline Love sweet food* & & 0.807 & & \\
\hline $\begin{array}{l}\text { Amount of sugar added to } \\
\text { tea† }\end{array}$ & & 0.621 & & \\
\hline Dietary sweet carbohydrates* & & & 0.833 & \\
\hline Dietary $\mathrm{Na}$ content ${ }^{*}$ & & & 0.800 & \\
\hline $\mathrm{FE}_{\mathrm{Na}}$ & & & & 0.681 \\
\hline $\begin{array}{l}\text { Salty snacks eaten (relative to } \\
\text { sweet snacks) } \dagger\end{array}$ & & & & 0.598 \\
\hline Salting food* & 0.468 & & & 0.570 \\
\hline Love salty food* & 0.551 & & & 0.552 \\
\hline
\end{tabular}

$\mathrm{FE}_{\mathrm{Na}}$, Fractional excretion of $\mathrm{NaCl}$.

${ }^{*}$ Questionnaire scores.

†Behavioural tests.
2002). Thus, physiological $\mathrm{Na}$ need, within normal limits or below, past or present, may contribute to the palatability of salt. We should note that there are other possible physiological determinants of salt palatability: the hormones of reproduction and the density of lingual papillae (Brown \& Toma, 1986; Bowen, 1992; Frye \& Demolar, 1994; Bartoshuk et al. 1998; Bartoshuk 2000; Duffy et al. 1998), but it is not currently known how these might interact with $\mathrm{Na}$ need.

\section{Palatability of salt in human subjects: nature or nurture?}

Yet more careful studies are certainly required to bolster the case for need-regulated palatability in human subjects, but the question of whether salt palatability is nature or nurture is as restrictive as that discussion ever was. Adolescent salt-wasting patients with congenital adrenal hyperplasia have a greater salt appetite: they find it more palatable, less aversive at high concentrations and ingest more of it than their siblings, but only when they are not therapeutically balanced because of non-compliance. They are thus responding to their Na loss, possibly via an adrenocorticotropic hormone stimulatory action, since their adrenocorticotropic hormone levels and salt appetite correlate. But on questioning, most report initiation of salt intake in childhood rather than infancy: half report that they learned to do so from others and half discovered they liked salt themselves. For example, one salt-wasting patient told us she discovered she liked salt in a kindergarten taste experiment. This could be taken to suggest that eating salt to ameliorate hyponatraemic crisis, as well as to prevent it, is an acquired strategy, possibly reinforced by heightened palatability. Moreover, most of the patients seem to prefer this living on the edge to taking their medicine (Kochli et al. 2002). Thus, self-medication with palatable salt might be inbred in man too.

\section{Palatability of food in relation to biological needs}

The discussion of Na-specific appetites highlights how a nutritional need for $\mathrm{Na}$ induces increases in the palatability of Na-rich items in many animals, and shows how similar mechanisms might apply in man. Yet, importantly, it also resolves the apparent paradox of how the palatability of salt can be dissociated from need, i.e. need may increase the palatability of salt when it is long dissociated from the need state.

The same principle of nutritional need leading to increased palatability has long been discussed in the more general context of why foods that are a reliable source of energy are generally liked. Indeed, such arguments were central to classic models of appetite regulation, especially those who saw body weight set-point as central concepts in appetite control (Nisbett, 1972; Cabanac, 1989). The notion that energetic need is integrated with sensory evaluation to determine palatability and so direct food choice and intake has obvious attractions, since it provides an elegant, testable model. Critical to models that have developed from this basic idea is the general principle that when the body is in need of energy, the palatability of 
any food that is a potential source of energy will be enhanced and, conversely, when no such need states exist palatability will be reduced. Arguably, the most explicit version of these models is the concept of negative gustatory alliesthesia, where a liking particularly for sweet tastes has been shown to vary as a function of level of satiety (Cabanac, 1989). The similarity between the concept of negative gustatory alliesthesia for sweet tastes and the concept of enhanced liking for salty tastes when in salt-need is compelling and fits with a broader view of the physiological role of pleasure (Cabanac, 1971). However, as with the earlier evaluation of human salt appetite, there is an alternative view of palatability that divorces, at least to some extent, the sensory stimulation of appetite through palatability and the notion that palatability simply reflects internal needs states. Thus, the concept of spontaneous (need-free) salt appetite may relate to a broader, hedonic model of palatability. The next section therefore evaluates in detail the case for need-free hedonic components to appetite control.

\section{Palatability and the hedonics of eating}

The observation that palatability is associated with greater food intake is well documented in studies on human subjects (Bellisle et al. 1984; Bobroff \& Kissileff, 1986; Guy-Grand et al. 1989; Spiegel et al. 1989; Helleman \& Tuorila, 1991; Tuorila et al. 1994; Yeomans, 1996; Yeomans et al. 1997; de Graaf et al. 1999; De Castro et al. 2000a,b) and has been widely reviewed (Young, 1967; Kissileff, 1976; Le Magnen, 1987; Drewnowski, 1998; Yeomans, 1998). This observation can be tautological: palatability is defined as the sensory stimulation of appetite, but without an independent measure of palatability (particularly in animal studies), increased intake is the evidence both for the difference in palatability and the effect of palatability on intake. However, this circularity can be avoided either if differences in palatability (in terms of hedonic evaluation for example) are established before the intake test, or if a specific mechanism underlying the short-term enhancement of food intake through palatability is evident. Human studies have provided evidence to meet both these criteria. The most common method for achieving differences in palatability independent of nutritional content is to simply alter the flavour of the ingested food (Bellisle et al. 1984; Bobroff \& Kissileff, 1986; Spiegel et al. 1989; Yeomans, 1996; Yeomans et al. 1997). In all cases, the degree to which flavour is rated as palatable (based on hedonic evaluation) at the start of a meal predicts overall food consumption. Moreover, the relationship appears to follow a linear function between the degree of difference in rated palatability at the start and overall intake (Bobroff \& Kissileff, 1986; Yeomans et al. 1997). Thus, manipulations of palatability in the absence of differences in nutrition have predictable effects on short-term intake. At a behavioural level, these changes in flavour also produce measurable differences in the pattern of change of rated appetite within a meal (Yeomans, 1996; Yeomans et $a l$. 2001b), with hunger tending to increase in the early stages of meals that are rated above neutral in terms of palatability (Fig. 2). Rated appetite

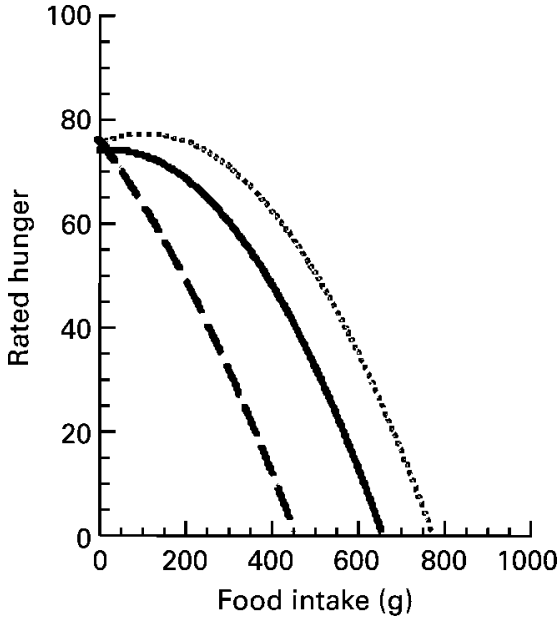

Fig. 2. Changes in rated hunger for normal-weight men eating a palatable $(\cdots)$, bland $(-)$ or overly strong-flavoured $\left(--_{-}\right)$test meal. (Modified from Yeomans 1996.)

can also be enhanced merely by the sight of a preferred food (Hill et al. 1984), suggesting immediate modulation of appetite by palatability. Manipulations that increase food pleasantness also enhance eating rate (Bellisle \& Le Magnen, 1980; Spiegel et al. 1989; Yeomans, 1996), as well as overall length of meals (Spiegel et al. 1989; Yeomans, 1996).

If this stimulatory effect of palatability was the consequence of stimulation of brain pathways associated with orosensory reward mechanisms, then disruption of these pathways should modify the response to palatability. Models of reward highlight three putative neurotransmitter systems: dopamine (Berridge, 1996), endogenous opioid peptides (Cooper \& Kirkham, 1990; Kelley et al. 2002; Yeomans \& Gray, 2002) and most recently endocannabinoids (Kirkham \& Williams, 2001). Of these, only opioid systems have been explored using pharmacological modulation in human subjects, but the outcome of these studies supports the idea that palatability reflects stimulation of central reward pathways by orosensory cues. Thus, opiate receptor antagonists reduce the rated pleasantness of food flavours (Yeomans et al. 1990; Bertino et al. 1991; Yeomans \& Wright, 1991; Drewnowski et al. 1992; Yeomans \& Gray, 1996; Arbisi et al. 1999), and the opioid antagonist naltrexone reversed the stimulatory effects of palatability on appetite (Yeomans \& Gray, 1997). The idea that palatability operates through orosensory reward is also well supported by animal studies (Berridge, 1996). Future human studies might usefully evaluate the contributions of other components of putative brain-reward pathways and the specific neuroanatomy of orosensory reward.

In the homeostatic approach to energy balance, drives (such as hunger) that arise in part from biological needs are balanced by physiological satiety signalling systems. The substrate comprises a network of neuropeptides and biogenic aminergic neurotransmitters that links peripheral and central components. This system has been well characterised (Hellström et al. 2004), and involves insulin, leptin, neuropeptide $\mathrm{Y}$, agouti gene-related peptide, $\alpha$-melanocyte stimulating hormone, cocaine- and amphetamine-regulated 
transcript, orexins, ghrelins, peptide YY and other peptides, along with serotonin pathways and other aminergic systems. Are the circuits for energy homeostasis and hedonic mediation independent of each other? Pharmacological evidence suggests that the circuits are rather separate. For example, in obese subjects administration of the serotonin drug d-fenfluramine (Blundell \& Hill, 1987) suppressed the sensation of hunger, but had no effect on the appreciation of the pleasantness of food. Conversely, opioid antagonists reduce the rated pleasantness of palatable foods, but have no effect on hunger (Yeomans \& Gray, 2002). This double dissociation indicates that appreciation of palatability is associated with a specific biological substrate that can be pharmacologically dissected from the substrate mediating hunger (Blundell \& Rogers, 1991). However, it is still possible for a functional interaction to occur when the manipulation is made through the natural commodity (namely food) rather than through a more selective artificial pharmaceutical manipulation.

\section{Palatability, satiation and satiety}

If neural system underlying orosensory reward and homeostatic controls of eating are dissociable, how then do these systems interact? Orosensory reward and satiety may operate independently, and therefore manipulations of these two systems should have additive effects. Alternatively, homeostatic needs (low levels of satiety) might magnify the effects of orosensory reward and thereby enhance the effects of palatability. One strategy for addressing this issue is to examine how manipulations of pre-test energy consumption modulate both the pleasantness of a subsequent test meal and the relationship between pleasantness and intake within that meal. This approach is clearest in preload studies, where a fixed energy load is followed by an ad libitum test meal, especially where differences in pre-test preload energy are appropriately disguised. If food pleasantness reflects the current level of need for energy, pleasantness of a test meal should be lower after a highenergy than a low-energy preload. However, while there have been some studies where test meal pleasantness was reduced after high-energy preloads (Booth et al. 1982; Johnson \& Vickers, 1993; Kim \& Kissileff, 1996), other studies report no effect of preload energy on the rated pleasantness of a test meal, despite compensatory reductions in subsequent energy intake (Birch \& Deysher, 1986; Vandewater \& Vickers, 1996; Yeomans et al. 1998, 2001a,b; Raynor \& Epstein, 2000). Thus, enhanced satiety does not reliably produce reductions in subsequent food pleasantness.

The same preloading design has also been combined with manipulations of palatability at the test meal to explore the interactive effects of palatability and satiety (Yeomans et al. 2001b; Robinson et al. 2004). The results suggest that orosensory stimulation decreases the ability of shortterm satiety cues generated by moderate energy preloads to reduce intake, resulting in an increase in overall energy intake in conditions where moderate-energy fat or carbohydrate preloads were combined with a test meal with enhanced flavour (Fig. 3). These results not only confirm that satiety and orosensory stimulation have opposing effects on short-term food intake, but also suggest that palatability
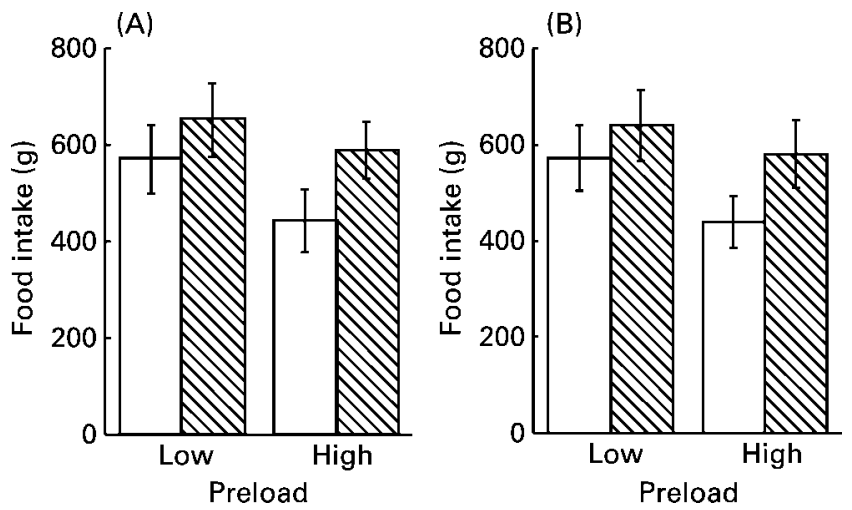

Fig. 3. Intake of a palatable $(\square)$ and bland ( $\mathbb{Q}$ ) food after low- and high-energy carbohydrate $(A)$ and fat $(B)$ preloads. (Modified from Yeomans et al. 2001.)

has a greater influence in conditions where satiety is enhanced, contradicting ideas that satiety and orosensory reward have either additive or positively interacting effects. The implication is that palatability may lead to over-consumption, particularly when sated. This conclusion is further supported by the observation that when intake of a preload was enhanced through a palatability manipulation, adequate compensatory reductions in intake were not seen at a subsequent test, resulting in over-consumption following highpalatability preloads (de Graaf et al. 1999).

An alternative to preloading as a manipulation of needstate is simply to increase the time since the previous meal (deprivation state). As with satiety, the effects of deprivation state on palatability are ambiguous. Some studies report enhanced increased palatability of food under conditions of deprivation (Spiegel et al. 1989), but an interesting recent study that attempted to separate reinforcing value from hedonic evaluation of food suggested that deprivation enhanced the reinforcing properties of foods without altering hedonic evaluations (Epstein et al. 2003). This distinction between reinforcement and hedonic influences fits well with theories of motivation originating in the drug-abuse literature (Berridge \& Robinson, 1998), and fits with the increasing belief that food and drugs share a common underlying reward system (Berridge, 1996; Carr, 1996; Grigson, 2002).

Although the idea that satiation and palatability operate independently is well supported by the results reviewed so far, one counter-argument is to highlight the subtlety of these interactions. In contrast, rated palatability, or more precisely rated pleasantness (Yeomans \& Symes, 1999), declines in a predictable manner within a meal, an observation consistent with Cabanac's concept of alliesthesia, and could be interpreted as palatability reflecting underlying homeostatic needs. However, the observation that liking for the consumed item declines more than for uneaten items (Rolls et al. 1981) contradicts this conclusion, since in a sated state any energy-rich food should be liked less than when hungry. Since changes in homeostatic needs following ingestion should peak some time after the end of a meal, sensory-specific satiety appears the more plausible mechanism to explain decreases in pleasantness during a meal, possibly as a means to counter palatability-induced over-consumption. 


\section{Pleasure of eating: a risk factor for weight gain?}

At the outset it is useful to pose some questions in order to focus attention on certain key issues. First, do people who gain weight and become obese have a different response to the palatability of food compared with people who remain lean? If the answer to this question is yes, then do obese people perceive food as being more or less pleasant than lean people? Put another way, do obese people have a suppressed or a super-sensitive response to the palatability of food? These questions are theoretically important, since both possibilities could account for over-eating among obese people. If food is perceived as being low in pleasantness, then it could be argued that people would need to eat more food in order to gain an adequate level of pleasure. Conversely, if food is perceived as being very pleasant, then this would stimulate more eating in order to gain maximal pleasure. The attraction of foods probably involves motives of 'liking' (reward) and 'wanting' (incentive salience) (Berridge \& Robinson, 1998), qualities that are difficult to dissect in human subjects.

Second, how can the biological purpose of eating be reconciled with the strong social, cultural and psychological aspects? As noted in the recent National Nutrition Health Programme (2001-2005) in France, an individual's food choice is a 'free act' and eating is recognised as a moment of pure pleasure. 'Must we from now on sacrifice the gentle principle of pleasure to the all powerful precautionary principle?'

A key proposal is that the palatability of foods constitutes a behavioural risk factor that promotes over-consumption. Although 'sedentariness' is widespread, there is also much evidence that weight-gaining individuals consume excessive amounts of food (Pearcey \& de Castro, 2002) and that weight gain is associated with specific food habits, including the consumption of fatty foods, eating outside the home and the availability of fast foods. Physiological satiety signals can be overwhelmed by the potency of energy-dense highly palatable foods (Blundell et al. 1996) and preferences for these foods are expressed as behavioural traits or risk factors (Blundell \& Gillett, 2001). Do these particular food habits stimulate eating either wholly or in part via the high palatability that forms an important part of their appeal?

\section{Food choice, palatability and obesity}

In addition to an interaction between palatability and hunger, the perceived pleasantness of foods could also modulate appetite control indirectly by influencing the choice of foods. There is considerable evidence that this is the case. In an experiment in which subjects sampled a range of foods containing varying amounts of fat and rated their sensory preferences, there was a positive relationship between the rated pleasantness of the fat content of the foods and measures of the adiposity of the subjects (Mela \& Sacchetti, 1991). The fatter the subjects, the greater their ratings of pleasantness for the fatty foods. More recently, the food choices of monozygotic twins discordant for body weight have been assessed (Rissanen et al. 2002). The twins with the highest degree of fatness displayed a significantly higher preference for fatty foods. If it is assumed that the expression of food preferences is influenced at least in part by the pleasure yielded by the foods, then these studies have demonstrated that levels of body fat are associated with a greater rating of pleasantness of fat-containing foods. In addition, female obese subjects have demonstrated a significantly higher preference for sweet high-fat foods than lean subjects (Drewnowski, 1992). In addition, using the database from a national food survey in the UK, it has been shown that obese subjects $\left(\mathrm{BMI} \geq 30 \mathrm{~kg} / \mathrm{m}^{2}\right)$ reported a greater consumption of sweet high-fat foods than subjects with lower BMI (Macdiarmid et al. 1996). However, this relationship only emerged after the suspected under-reporters had been removed from the database, leaving only subjects whose reports were likely to be more valid. Taken together, these findings indicate that palatability of foods promotes the choice of foods (high in fat) that are known to favour the attainment of a positive energy balance. Obese individuals appear to be particularly vulnerable to display this maladaptive food choice process.

These studies indicate that palatability can influence appetite control (and therefore food intake) via effects on food choice or on energy intake (via hunger). Recent investigations of behavioural phenotypes characterised by habitual food choices suggest that these phenomena can coexist. Groups of obese and lean young male subjects matched for age and the habitual high consumption of fat (high-fat phenotypes) were compared (Le Noury et al. 2002). Although both groups were eating a diet known to favour a positive energy balance, the obese phenotypes consumed greater amounts of the high-fat foods in a test meal and reported greater feelings of pleasantness, satisfaction and tastiness for the foods consumed. One interpretation of these results is that, for a least one group of obese people, they habitually self-select (fatty) foods with a high probability of generating a positive energy balance (on the basis of their energy density), consume these foods in greater amounts and derive greater pleasure from this eating. This outcome also demonstrates that obese people have a disposition to perceive foods as being more pleasant than their lean counterparts. This may indicate a super sensitivity in components of the neural circuitry forming the substrate for hedonic properties of foods. Given this capacity to obtain a high level of pleasure from foods (and eating), it is not surprising that obese people show a tendency to self-select high palatability foods. There is evidence that dopamine D2 receptors (implicated in hedonic processes) are altered in obese individuals (Wang et al. 2001) although the interpretation of these results may be complicated (Berridge \& Robinson, 1998).

\section{The palatability dilemma}

The evidence indicating a role for palatability in appetite control creates a problem for nutritional strategies to deal with obesity. Within the field of functional foods (or nutriceuticals) there is a strong movement to produce foods that will enhance satiety. However, the food industry is also committed to producing foods that are highly palatable; this will have the intended effect of promoting acceptability and consumption (see results earlier). Palatability increases 
the willingness of people to consume (and carries the potential to over-consume). This means that within a particular food, different components may enhance and diminish the disposition to eat. Is this achievable? Is it possible to design foods with enhanced palatability (to promote and ensure consumption) and at the same time to improve satiety (which implies a reduction in the desire to eat)?

\section{Pharmaceutical strategies}

Although low levels of physical activity contribute to body-weight gain, there is no doubt that many weightgaining and obese individuals display behavioural risk factors, such as patterns of eating, food selection, weak satiety and a recurring drive to eat, which favour the attainment of a positive energy balance (Blundell \& Cooling, 2000). To these risk factors should be added a supersensitive hedonic capacity. Currently, pharmaceutical strategies for the treatment of obesity are concerned with the reduction of energy assimilated, by improving satiety (sibutramine) or by reducing fat intake and fat digestion (Orlistat). Given the evidence cited earlier, some consideration should be given to the concept of diminishing the hedonic response to foods, particularly in the light of the ever-increasing palatability of foods entering the market place. The strategy would counter one significant risk factor that predisposes people to gain weight. The identification of a neural substrate that mediates aspects of the hedonic response, reward value of foods or their incentive salience, identifies pharmacological targets. Of particular interest are the endocannabinoids, which are known to be involved in food consumption and especially the intake of highly palatable foods (Kirkham \& Williams, 2001). CB1 receptor antagonists such as SR141716A (Rimonabant) may be effective in helping people to diminish consumption of high-risk foods, adapt to more appropriate food choices and resist cravings. This type of approach would add a useful dimension to pharmaceutical treatments and may be especially helpful for a subset of obese people who over-consume because of a potent hedonic response to food.

\section{Summary}

The overall conclusion from the present brief review is that homeostatic models that interpret palatability as a reflection of underlying need-state are inadequate. Whether we examine salt appetite, where the physiological imperative to relate the palatability of a specific ion $(\mathrm{Na})$ to the bodily need-state for that ion, or look more broadly at the use of foods in general, the recurring theme in the present review is that the preference for specific foods in man appears to reflect need-free hedonic stimulation of appetite, rather than a specific appetite arising from a specific need-state.

An important issue is what makes a food taste palatable. The most widely cited models in appetite research suggest palatability arises through past associations between flavours and consequences, most explicitly in flavour preference conditioning (Booth, 1991; Capaldi, 1992; Sclafani, 1999). An important finding in the present review of liking for salty tastes was the observation that even a single experience of salt deprivation in childhood can lead to an enduring increase in liking for salty tastes in the absence of salt-need in adulthood. Accordingly, need-state may result in acquired palatability, but needstate may not be necessary for the subsequent expression of palatability. Attractive though this idea is, the limited results on acquired flavour preferences in human subjects suggest that preferences for flavours acquired when hungry or in a protein-deprived state are not expressed when sated (Booth et al. 1982; Gibson et al. 1995). Similarly, association of a flavour with caffeine can result in increased liking for that flavour if in need of caffeine, but this acquired palatability is not expressed when in a caffeine-sated state (Yeomans et al. 2000). These limited results argue against a generalised rule that need-state may enhance palatability, but this acquired liking is then insensitive to subsequent need-state. However, further research is needed to verify this conclusion, especially since, as discussed here, over-consumption of palatable foods is implicated in the development of obesity.

The present review also highlights the need for treatment strategies for obesity that incorporate our understanding of obesity. While reducing the palatability of our diet should result in reduced food consumption, in practice this is clearly not an option. However, designing diets that maximise hedonic satisfaction, but enhance satiation and/or satiety, is a novel and potentially useful strategy. Likewise, accepting that obesity cannot easily be attributed to a breakdown of homeostatic control mechanisms (Hellström et al. 2004) suggests that alternative pharmaceutical strategies aimed at modifying hedonic components of eating is also a strategy worth pursuing, especially with the merging role of cannabinoids in appetite control. At the same time, some of the shortcomings in our understanding of the nature of palatability highlighted in the present review need addressing. Until we have a clear model of what makes a food palatable, and how this leads to over-consumption, we will not be in a position to utilise these ideas to properly develop novel treatment strategies for obesity.

\section{Acknowledgements}

The Israel-USA Binational Foundation supported work on salt appetite by Alan Epstein, Eliot Stellar and M. L. The Israel Academy of Sciences and Israel Ministry of Health supported M. L. Research on palatability was supported by grants from BBSRC to M. R. Y. Part of the work of J. E. B. forms part of The Diet and Obesity Project funded by the European Union under Quality of Life and Management of Living Resources (QLK1-CT-2000-00515). J. E. B. thanks Joanna Le Noury and Dr Clare Lawton.

\section{References}

Arbisi PA, Billington CJ \& Levine AS (1999) The effect of naltrexone on taste detection and recognition threshold. Appetite 32, 241-249.

Arguelles J, Brime JI, Lopes-Sela P, Perillan C \& Vijande M 
(1999) Adult offspring long-term effects of high salt and water intake during pregnancy. Horm Behav 37, 156-162.

Ayya N \& Beauchamp GK (1992) Short-term effects of diet on salt taste preference. Appetite 18, 77-82.

Bartoshuk LM (2000) Comparing sensory experiences across individuals: recent psychophysical advances illuminate genetic variation in taste perception. Chem Senses 25, 447-460.

Bartoshuk LM, Duffy VB, Lucchina LA, Prutkin J \& Fast K (1998) PROP (6-n-propylthiouracil) supertasters and the saltiness of NaCl. Ann NY Acad Sci 855, 793-796.

Beauchamp GK, Bertino M, Burke D \& Engelman K (1990) Experimental sodium depletion and salt taste in normal human volunteers. Am J Clin Nutr 51, 881-889.

Beauchamp GK, Bertino M \& Engelman K (1987) Failure to compensate decreased dietary-sodium with increased table salt usage. J Am Med Assoc 258, 3275-3278.

Beauchamp GK, Bertino M \& Engelman K (1991) Human salt appetite. In Appetite and Nutr, pp. 85-107 [MI Friedman, MG Tordoff and MR Kare, editors]. New York: Dekker.

Beauchamp GK, Reed DR, Tordoff MG \& Bachmanov AA (2002) Genetics of sweet taste. In Chemistry of Taste: Mechanisms, Behaviors, and Mimics, vol 825 pp. 40-51 [P Given and D Paredes, editors]. Washington DC: Oxford University Press.

Bellisle F \& Le Magnen J (1980) The analysis of human feeding patterns: the Edogram. Appetite 1, 141-150.

Bellisle F, Lucas F, Amrani R \& Le Magnen J (1984) Deprivation, palatability and the micro-structure of meals in human subjects. Appetite 5, 85-94.

Berridge KC (1996) Food reward: brain substrates of wanting and liking. Neurosci Biobehav Rev 20, 1-25.

Berridge KC, Flynn FW, Schulkin J \& Grill HJ (1984) Sodium depletion enhances salt palatability in rats. Behav Neurosci 98, 652-660.

Berridge KC \& Robinson TE (1998) What is the role of dopamine in reward: hedonic impact, reward learning, or incentive salience? Brain Res Bull 28, 309-369.

Berridge KC \& Schulkin J (1989) Palatability shift of a saltassociated incentive during sodium depletion. $Q J$ Exp Psychol 41B, 121-138.

Bertino M, Beauchamp GK \& Engelman K (1982) Long-term reduction in dietary sodium alters the taste of salt. Am J Clin Nutr 36, 1134-1144.

Bertino M, Beauchamp GK \& Engelman K (1986) Increasing dietary salt alters salt taste preference. Physiol Behav 38, 203-213.

Bertino M, Beauchamp GK \& Engelman K (1991) Naltrexone, an opioid blocker, alters taste perception and nutrient intake in humans. Am J Physiol 261, R59-R63.

Birch LL \& Deysher M (1986) Caloric compensation and sensory-specific satiety: evidence for self-regulation of food intake by young children. Appetite 7, 323-331.

Blundell JE \& Cooling J (2000) Routes to obesity: phenotypes, food choices and activity. Br J Nutr 83, Suppl. 1, S33-S38.

Blundell JE \& Gillett A (2001) Control of food intake in the obese. Obes Res 9, 263S-270S

Blundell JE \& Hill AJ (1987) Serotoninergic modulation of the pattern of eating and the profile of hunger-satiety in humans. Int J Obes 11, Suppl. 3, 141-155.

Blundell JE, Lawton CL, Cotton JR \& Macdiarmid JI (1996) Control of human appetite - implications for the intake of dietary-fat. Annu Rev Nutr 16, 285-319.

Blundell JE \& Rogers PJ (1991) Hunger, hedonics, and the control of satiation and satiety. In Appetite and Nutrition, pp. 127-148 [MI Friedman, MG Tordoff and MR Kare, editors]. New York: Dekker.

Bobroff EM \& Kissileff H (1986) Effects of changes in palatability on food intake and the cumulative food intake curve of man. Appetite 7, 85-96.

Booth DA (1991) Learned ingestive motivation and the pleasures of the palate. In The Hedonics of Taste [RC Bolles, editor]. Hillside, NJ: Lawrence Erlbaum Associates.

Booth DA, Mather P \& Fuller J (1982) Starch content of ordinary foods associatively conditions human appetite and satiation, indexed by intake and pleasantness of starch-paired flavours. Appetite 3, 163-184.

Bowen DJ (1992) Taste and food preference changes across the course of pregnancy. Appetite 19, 233-242.

Breslin PAS \& Beauchamp GK (1995) Suppression of bitterness by sodium: variation among bitter taste stimuli. Chem Senses 20, 609-623.

Brown JE \& Toma RB (1986) Taste changes during pregnancy. Am J Clin Nutr 43, 414-418.

Cabanac M (1971) Physiological role of pleasure. Science 173, $1103-1107$.

Cabanac M (1989) Palatability of food and the ponderostat. Ann NY Acad Sci 575, 340-352.

Capaldi ED (1992) Conditioned food preferences. Psychol Learn Motiv 28, 1-33.

Carr KD (1996) Feeding, drug abuse and the sensitization of reward by metabolic need. Neurochem Res 21, 1455-1467.

Cooper SJ \& Kirkham TC (1990) Basic mechanisms of opioids' effects on eating and drinking. In Opioids, Bulimia and Alcohol Abuse and Alcoholism, pp. 91-110 [LD Reid, editor]. New York: Springer-Verlag.

Cowart BJ \& Beauchamp GK (1986) The importance of sensory context in young children's acceptance of salty tastes. Child Dev 57, 1034-1039.

Crystal SR \& Bernstein IL (1995) Morning sickness: impact on offspring salt preference. Appetite 25, 231-240.

Crystal SR \& Bernstein IL (1998) Infant salt preference and mother's morning sickness. Appetite 30, 297-307.

Crystal SR, Bowen DJ \& Bernstein IL (1999) Morning sickness and salt intake, food cravings, and food aversions. Physiol Behav 67, 181-187.

Curtis KS, Krause EG \& Contreras RJ (2001) Altered $\mathrm{NaCl}$ taste responses precede increased $\mathrm{NaCl}$ ingestion during $\mathrm{Na}(+)$ deprivation. Physiol Behav 72, 743-749.

Davis JD \& Levine MW (1977) A model for the control of ingestion. Psychol Rev 84, 379-412.

De Castro JM, Bellisle F \& Dalix A-M (2000a) Palatability and intake relationships in free-living humans: measurement and characterisation in the French. Physiol Behav 68, 271-277.

De Castro JM, Bellisle F, Dalix A-M \& Pearcey SM (2000b) Palatability and intake relationships in free-living humans: characterization and independence of influence in North Americans. Physiol Behav 70, 343-350.

De Graaf C, de Jong LS \& Lambers AC (1999) Palatability affects satiation but not satiety. Physiol Behav 66, 681-688.

Denton D, Weisinger R, Mundy NI, et al. (1995) The effect of increased salt intake on blood pressure of chimpanzees. Nat Med 1, 1009-1016.

Denton DA (1982) The Hunger for Salt. Berlin: Springer-Verlag.

Denton DA, Eichberg JW, Shade R \& Weisinger RS (1993) Sodium appetite in response to sodium deficiency in baboons. Am J Physiol 264, R539-R543.

Doucet E \& Tremblay A (1997) Food intake, energy balance and body weight control. Eur J Clin Nutr 51, 846-855.

Drewnowski A (1992) Sensory preferences and fat consumption in obesity and eating disorders. In Dietary Fats: Determinants of Preference, Selection and Consumption, pp. 59-77 [DJ Mela, editor]. London: Elsevier.

Drewnowski A (1998) Energy density, palatability and satiety: implications for weight control. Nutr Rev 56, 347-353. 
Drewnowski A (2002) Genetic markers, taste responses, and food preferences. In Chemistry of Taste: Mechanisms, Behaviors, and Mimics, vol. 825 pp. 52-64 [P Given and D Paredes, editors]. Washington DC: Oxford University Press.

Drewnowski A, Krahn DD, Demitrack MA, Nairn K \& Gosnell BA (1992) Taste responses and preferences for sweet high-fat foods: evidence for opioid involvement. Physiol Behav 51, 371-379.

Duffy VB, Bartoshuk LM, Striegel-Moore R \& Rodin J (1998) Taste changes across pregnancy. Ann NY Acad Sci 855, 805-809.

Epstein AN (1991) Thirst and salt intake: a personal view and some suggestions. In Thirst - Physiological and Psychological Aspects, pp. 481-501 [DJ Ramsay and DA Booth, editors]. Berlin: Springer-Verlag.

Epstein LH, Truesdale R, Wojcik A, Paluch RA \& Raynor HA (2003) Effects of deprivation on hedonics and reinforcing value of food. Physiol Behav 78, 221-227.

Falk JL (1966) Serial sodium depletions and $\mathrm{NaCl}$ solution intake. Physiol Behav 1, 75-77.

Farleigh CA, Shepherd R, Jevons S \& Pryor JS (1987) Effects of haemodialysis on taste for salt in relation to changes in blood constituents. Hum Nutr Clin Nutr 41, 441-451.

Fluharty SJ \& Epstein AN (1983) Sodium appetite elicited by intracerebroventricular infusion of angiotensin II in the rat: II. Synergistic interaction with systemic mineralocorticoids. Behav Neurosci 97, 746-758.

Frye CA \& Demolar GL (1994) Menstrual cycle and sex differences influence salt preference. Physiol Behav 55, 193-197.

Gibson EL, Wainwright CJ \& Booth DA (1995) Disguised protein in lunch after low-protein breakfast conditions food-flavor preferences dependent on recent lack of protein intake. Physiol Behav 58, 363-371.

Greenfield H, Maples J \& Wills RBH (1983) Salting of food - a function of hole size and location of shakers. Nature 301, $331-332$.

Grigson PS (2002) Like drugs for chocolate: separate rewards modulated by common mechanisms. Physiol Behav 76, 389-395.

Guy-Grand B, Lehner V \& Doassans M (1989) Effects of palatability and meal type on food intake in normal weight males. Appetite 12, 213-214.

Harris G, Thomas A \& Booth DA (1990) Development of salt taste in infancy. Dev Psychol 26, 534-538.

Helleman U \& Tuorila H (1991) Pleasantness ratings and consumption of open sandwiches with varying $\mathrm{NaCl}$ and acid contents. Appetite 17, 229-238.

Hellström PM, Geliebter A, Näslund E, Schmidt PT, Gluck M, Yahav E, Hashim SA \& Yeomans MR (2004) Peripheral and central signals in the control of eating in normal, obese and binge-eating human subjects. Br J Nutr 92, Suppl. 1, 000-000.

Henkin RI, Gill JR \& Bartter FC (1963) Studies on taste thresholds in normal man and in patients with adrenal cortisol insufficiency: the role of adrenal cortical steroids and of serum concentration. J Clin Invest 42, 727-735.

Hill AJ, Magson LD \& Blundell JE (1984) Hunger and palatability: tracking ratings of subjective experience before, during and after the consumption of preferred and less preferred food. Appetite 5, 361-371.

Huggins RL, Nicolantonio RD \& Morgan TO (1992) Preferred salt levels and salt taste acuity in human subjects after ingestion of untasted salt. Appetite 18, 111-119.

Jacobs KM, Mark GP \& Scott TR (1988) Taste responses in the nucleus tractus solitarius of sodium-deprived rats. $J$ Physiol 406, 393-410.
Jequier E \& Tappy L (1999) Regulation of body weight in humans. Physiol Rev 79, 451-480.

Johnson AK \& Thunhorst RL (1997) The neuroendocrinology of thirst and salt appetite: visceral sensory signals and mechanisms of central integration. Front Neuroendocrinol 18, $292-353$.

Johnson J \& Vickers Z (1993) Effects of flavor and macronutrient composition of food servings on liking, hunger and subsequent intake. Appetite 21, 25-39.

Kanarek RB, Ryu M \& Przypek J (1995) Preferences for foods with varying levels of salt and fat differ as a function of dietary restraint and exercise but not the menstrual cycle. Physiol Behav 57, 821-826.

Kelley AE, Bakshi VP, Haber SN, Steininger TL, Will MJ \& Zhang M (2002) Opioid modulation of taste hedonics within the ventral striatum. Physiol Behav 76, 365-377.

Kim JY \& Kissileff HR (1996) The effect of social setting on response to a preloading manipulation in nonobese women and men. Appetite 27, 25-40.

Kirkham TC \& Williams CM (2001) Endogenous cannabinoids and appetite. Nutr Res Rev 14, 65-86.

Kissileff HR (1976) Palatability. In International Encyclopedia of Psychiatry, Psychology, Psychoanalysis and Neurology, pp. 172. New York: Academic Press.

Kissileff HR (1990) Some suggestions on dealing with palatability - response to Ramirez. Appetite 14, 162-166.

Kochli A, Rakover Y \& Lesham M (2002) Perinatal dehydration correlates with adolescent salt preference. Neural Plast 9, 94.

Le Magnen J (1987) Palatability: concept, terminology and mechanisms. In Eating Habits: Food, Physiology and Learned Behaviour, pp. 131-154 [RA Boakes, DA Popplewell and MJ Burton, editors]. Chichester, Sussex: Wiley.

Le Noury JC, Lawton C \& Blundell JE (2002) Food choice and hedonic responses: difference between overweight and lean high fat phenotypes. Int J Obes 26, S125.

Leshem M (1998) Salt preference in adolescence is predicted by common prenatal and infantile mineralofluid loss. Physiol Behav 63, 699-704.

Leshem M (1999) The ontogeny of salt hunger in the rat. Neurosci Biobehav Rev 23, 649-659.

Leshem M, Abutbul A \& Eilon R (1999) Exercise increases the preference for salt in humans. Appetite 32, 251-260.

Leshem M, Maroun M \& Del Canho S (1996) Sodium depletion and maternal separation in the suckling rat increase its salt intake when adult. Physiol Behav 59, 199-204.

Leshem M, Maroun M \& Weintraub Z (1998) Neonatal diuretic therapy may not alter children's preference for salt taste. Appetite 30, 53-64.

Leshem M \& Rudoy J (1997) Hemodialysis increases the preference for salt in soup. Physiol Behav 61, 65-69.

McCance RA (1936) Experimental sodium chloride deficiency in man. Proc $R$ Soc B 119, 245-268.

Macdiarmid JI, Cade JE \& Blundell JE (1996) High and low-fat consumers, their macronutrient intake and body-mass index further analysis of the national diet and nutrition survey of British adults. Eur J Clin Nutr 50, 505-512.

Mattes RD (1997) The taste for salt in humans. Am J Clin Nutr 65, 692S-697S.

Mattes RD, Christensen CM \& Engelman K (1990) Effects of hydrochlorothiazide and amiloride on salt taste and excretion (intake). Am J Hypertens 3, 436-443.

Mela DJ (2000) Why do we like what we like? J Sci Food Agric 81, 10-16.

Mela DJ \& Sacchetti DA (1991) Sensory preferences for fats relationships with diet and body-composition. Am J Clin Nutr 53, 908-915. 
Naim M \& Kare MR (1991) Sensory and postingestional components of palatability in dietary obesity: an overview. In Appetite and Nutrition, pp. 109-126 [MI Friedman, MG Tordoff and MR Kare, editors]. New York: Dekker.

Nicolaidis S, Galaverna O \& Metzler CH (1990) Extracellular dehydration during pregnancy increases salt appetite of offspring. Am J Physiol 258, R281-R283.

Nisbett RE (1972) Hunger, obesity and the ventromedial hypothalamus. Psychol Rev 79, 433-453.

Nose H, Mack GW, Shi X \& Nathan ER (1988) Involvement of sodium retention hormones during rehydration in humans. J Appl Physiol 65, 332-336.

Pangborn RM \& Pecore SD (1982) Taste perception of sodium chloride in relation to dietary intake of salt. Am J Clin Nutr 35, 510-520.

Pearcey SM \& de Castro JM (2002) Food intake and meal patterns of weight-stable and weight-gaining persons. Am J Clin Nutr 76, 107-112.

Ramirez I (1990) What do we mean when we say "palatable food"? Appetite 14, 159-161.

Raynor HA \& Epstein LH (2000) Effects of sensory stimulation and post-ingestive consequences on satiation. Physiol Behav 70, 465-470.

Rissanen A, Hakala P, Lissner L, Mattlar CE, Koskenvuo M \& Ronnemaa T (2002) Acquired preference especially for dietary fat and obesity: a study of weight-discordant monozygotic twin pairs. Int J Obes Relat Metab Disord 26, 973-977.

Robinson TM, Gray RW, Yeomans MR \& French SJ (2004) Testmeal palatability alters the effects of intragastric fat but not carbohydrate preloads on intake and rated appetite in healthy volunteers. Physiol Behav (In Press).

Rogers PJ (1990) Why a palatability construct is needed. Appetite 14, 167-170.

Roitman MF, Na E, Anderson G, Jones TA \& Bernstein IL (2002) Induction of a salt appetite alters dendritic morphology in nucleus accumbens and sensitizes rats to amphetamine. J Neurosci 22, RC225.

Rolls BJ, Rolls ET, Rowe EA \& Sweeney K (1981) Sensoryspecific satiety in man. Physiol Behav 27, 137-142.

Rowland NE \& Fregly MJ (1988) Sodium appetite: species and strain differences and role of renin-angiotensin-aldosterone system. Appetite 11, 143-178.

Rozin P \& Vollmecke TA (1986) Food likes and dislikes. Annu Rev Nutr 6, 433-456.

Sakai RR, Fine WB \& Epstein AN (1987) Salt appetite is enhanced by one prior episode of sodium depletion in the rat. Behav Neurosci 101, 724-731.

Sakai RR, Frankmann SP, Fine WB \& Epstein AN (1989) Prior episodes of sodium depletion increase the need-free sodium intake of the rat. Behav Neurosci 103, 186-192.

Schulkin J (1991) Sodium Hunger: The Search for a Salty Taste. Cambridge: Cambridge University Press.

Schulkin J (2003) Rethinking Homeostasis: Allostatic Regulation in Physiology and Pathology. Cambridge, MA: MIT Press.

Sclafani A (1999) Macronutrient-conditioned flavor preferences. In Neural Control of Macronutrient Selection, pp. 93-106 [H-R Berthoud and RJ Seeley, editors]. Boca Raton, FL: CRC Press.

Shepherd R, Farleigh CA \& Pryor JS (1986) Changes in salt taste in dialysis and their relationship to blood constituents. Percept Mot Skills 62, 343-347.

Shepherd R, Farleigh CA \& Wharf SG (1989) Limited compensation by table salt for reduced salt within a meal. Appetite 13, 193-200.

Spiegel TA, Shrager EE \& Stellar E (1989) Responses of lean and obese subjects to preloads, deprivation and palatability. Appetite 13, 46-69.

Stein LJ, Cowart BJ, Epstein AN, Pilot LJ, Laskin CR \& Beauchamp GK (1996) Increased liking for salty foods in adolescents exposed during infancy to a chloride-deficient feeding formula. Appetite 27, 65-77.

Steiner JE, Glaser D, Hawilo ME \& Berridge KC (2001) Comparative expression of hedonic impact: affective reactions to taste by human infants and other primates. Neurosci Biobehav Rev 25, 53-74.

Takamata A, Mack GW, Gillen CM \& Nadel ER (1994) Sodium appetite, thirst, and body fluid regulation in humans during rehydration without sodium replacement. Am J Physiol 266, R1493-R1502.

Tuorila H, Nyvonen L \& Vainio L (1994) Pleasantness of cookies, juice, and their combinations rated in brief taste tests and following ad libitum consumption. J Sens Stud 9, $205-216$.

Vandewater K \& Vickers Z (1996) Higher-protein foods produce greater sensory-specific satiety. Physiol Behav 59, $579-583$.

Verbalis JG (1990) Clinical aspects of body fluid homeostasis in humans. In Handbook of Behavioral Neurobiology, pp. 421-426 [EM Stricker, editor]. New York: Plenum Press.

Vijande M, Brime JI, Lopez-Sela P, Costales M \& Arguelles J (1996) Increased salt preference in adult offspring raised by mother rats consuming excessive amounts of salt and water. Regul Pept 66, 105-108.

Wald N \& Leshem M (2003) Salt conditions a flavor preference or aversion after exercise depending on $\mathrm{NaCl}$ dose and sweat loss. Appetite 40, 277-284.

Wang GJ, Volkow ND, Logan J, Pappas NR, Wong CT, Zhu W, Netusil N \& Fowler JS (2001) Brain dopamine and obesity. Lancet 357, 354-357.

Wilkins L \& Richeter CP (1940) A great craving for salt by a child with cortico-adrenal insufficiency. J Am Med Assoc 114, 866-868.

Yeomans MR (1996) Palatability and the microstructure of eating in humans: the appetiser effect. Appetite 27, 119-133.

Yeomans MR (1998) Taste, palatability and the control of appetite. Proc Nutr Soc 57, 609-615.

Yeomans MR \& Gray RW (1996) Selective effects of naltrexone on food pleasantness and intake. Physiol Behav 60, 439-446.

Yeomans MR \& Gray RW (1997) Effects of naltrexone on food intake and changes in subjective appetite during eating: evidence for opioid involvement in the appetiser effect. Physiol Behav 62, 15-21.

Yeomans MR \& Gray RW (2002) Opioids and human ingestive behaviour. Neurosci Biobehav Rev 26, 713-728.

Yeomans MR, Gray RW \& Conyers T (1998) Maltodextrin preloads reduce intake without altering the appetiser effect. Physiol Behav 64, 501-506.

Yeomans MR, Gray RW, Mitchell CJ \& True S (1997) Independent effects of palatability and within-meal pauses on intake and subjective appetite in human volunteers. Appetite 29, $61-76$.

Yeomans MR, Jackson A, Lee MD, Nesic JS \& Durlach PJ (2000) Expression of flavour preferences conditioned by caffeine is dependent on caffeine deprivation state. Psychopharmacology 150, 208-215.

Yeomans MR, Lartamo S, Procter EL, Lee MD \& Gray RW (2001a) The actual, but not labelled, fat content of a soup preload alters short-term appetite in healthy men. Physiol Behav 73, 533-540.

Yeomans MR, Lee MD, Gray RW \& French SJ (2001b) Effects of test-meal palatability on compensatory eating following 
disguised fat and carbohydrate preloads. Int $J$ Obes 25, 1215-1224.

Yeomans MR \& Symes T (1999) Individual differences in the use of palatability and pleasantness ratings. Appetite 32, 383-394.

Yeomans MR \& Wright P (1991) Lower pleasantness of palatable foods in nalmefene-treated human volunteers. Appetite 16, 249-259.

Yeomans MR, Wright P, Macleod HA \& Critchley JAJH (1990) Effects of nalmefene on feeding in humans: dissociation of hunger and palatability. Psychopharmacology 100, 426-432.

Young PT (1967) Palatability: the hedonic response to foodstuffs. In Handbook of Physiology, Section 6: Alimentary Canal, Vol. 1. Control of Food and Water Intake, pp. 353-366 [CF Code, editor]. Washington, DC: American Physiology Society.

Zellner DA (1991) How foods get to be liked: some general mechanisms and some special cases. In The Hedonics of Taste, pp. 199-217 [RC Bolles, editor]. Hillside, NJ: Lawrence Erlbaum Associates. 